\title{
Analisis Kelengkapan Formulir A (Evaluasi Awal MPP) Dan Formulir B (Catatan Implementasi) Pasien Rumah Sakit
}

\author{
Dicho Zhuhriano Yasli ${ }^{1}$, Devid Leonard ${ }^{2}$, Berly Nisa Srimayarti ${ }^{3}$ \\ ${ }^{1,2,3}$ Prodi S1 Administrasi Rumah Sakit, STIKes Dharma Landbouw Padang
}

\begin{tabular}{l}
\hline Article Info \\
\hline Article history: \\
Received Dec 21, 2020 \\
Revised Feb 15, 2021 \\
Accepted Feb 17, 2021 \\
\hline
\end{tabular}

Keywords:

Form A

Form B

Medical record file

Completeness

\begin{abstract}
ABSTRAK
The medical record file contains the identity, examination, action, service, and treatment given to patients. Incomplete filling in forms A and $\mathrm{B}$ during inpatient examinations is a problem that often arises in several hospitals. The purpose of this study was to conduct a literature review regarding the incomplete analysis in filling out form A for the Initial Evaluation of the MPP and form B for implementation notes. Secondary data collection methods with literature review approach, namely determining keywords, exploration and selection of titles, reading articles that have not been eliminated. The literature search was carried out by establishing inclusion and exclusion criteria. The results of the literature review, namely the incompleteness of filling out medical record forms, the responsibilities and attitudes of officers in filling out medical record files, are still not optimal. The human resources involved are still lacking, for example the assembling officer also serves the file preparation so that the assembly function is not optimal. Based on a literature review of several related articles, further research is needed regarding other causes of incomplete medical record file forms and the obstacles that doctors experience in filling out medical record files.
\end{abstract}

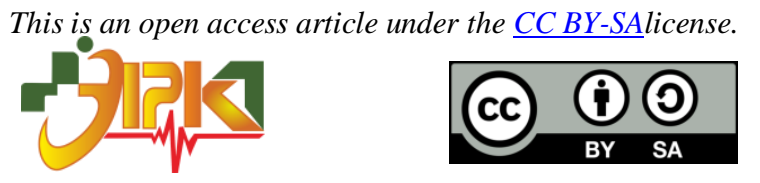

\section{Corresponding Author:}

Dicho Zhuhriano Yasli,

Prodi S1 Administrasi Rumah Sakit

STIKes Dharma Landbouw Padang,

Jl. Jhoni Anwar No. 29 Ulak Karang Utara, Kec. Padang Utara, Kota Padang, Sumatera Barat.

Email: dichozhuhriano@gmail.com

\section{PENDAHULUAN}

Rekam medis merupakan suatu dokumen atau berkas yang berisikan identitas pasien, hasil pemeriksaan, tindakan yang diberikan, bentuk pelayanan, serta pengobatan yang diberikan kepada pasien. Rekam medis pasien merupakan suatu catatan tertulis yang berisikan sejarah tentang kondisi fisik maupun pisikis (kesehatan) serang pasien, termasuk penyait yang diderita oleh pasien sekarang, maupun di masa lalu dan proses pengobatan yang dilakukan oleh pasien demi kesembuhannya terhadap penyakit atau gangguan yang diderita oleh pasien $[1,2]$.

Meningkatkan mutu informasi kesehatan, diperlukan kontribusi petugas rekam medis agar mampu dan bekerja dengan baik sesuai dengan aturan yang ada yaitu Kep Menkes 
Nomor 377/Menkes/SK/III/2007 tentang standar profesi rekam medis informasi kesehatan. Beberapa kegunaan dari berkas rekam medis diantaranya sebagai bukti diagnosa penyakit dan pengobatan yang diberikan kepada pasien, adanya bukti catatan komunikasi antar tenaga kesehatan dalam memberikan pelayanan dan perawatan, data rekam medis bisa digunakan untuk sumber informasi dalam dunia penedidikan [3]. Berkas rekam medis bisa dimanfaatkan dalam beberapa aspek diantaranya aspek medis, administrasi, penelitian, hukum, keuangan, dan bukti dokumentasi selama pasien di pelayanan kesehatan $[4,5,6]$.

Berkas rekam medis harus diisi secara lengkap oleh petugas kesehatan medis maupun non medis yang bersangkutan. Salah satu yang wajib mengisi berkas tersebut yaitu dokter, harus mengisi lengkap selama memberi pelayanan dalam kurun waktu $\leq 24$ jam, berkas diisi setelah diberikan pelayanan baik itu rawat jalan maupun rawat inap. Kelengkapan berkas juga dipengaruhi oleh isian form oleh pasien, yaitu berkas informed consent merupakan persetujuan yang harus diisi oleh pasien atau keluarga terkait dengan penjelasan tindakan medis yang akan diberikan kepada pasien [7]. Hal ini sejalan dengan Permenkes RI Nomor 1171 tahun 2011 tentang pedoman sistem informasi di pelayanan rumah sakit, yaitu semua jenis pelayanan yang diberikan kepada pasien baik rawat inap maupun rawat jalan harus diisi sesuai dengan jenis dan diagnosa kepada pasien tersebut [8]. Pengisian pelayanan di rumah sakit berdasarkan jenis dari ruangan tersebut atau sesuai dengan spesialisasinya. Rumah sakit yang hanya mempunyai satu ruangan saja, maka data yang diisikan disesuaikan dengan jenis yang diberikan pada pelayanan umum. Sedangkan bagi ruangan rawat inap, tingkat pelayanan yang diberikan sesuai rincian tingkat kelas pada perawatan. Bentuk standarisasi perawatan antar kelas tersebut ditentukan oleh masing-masing rumah sakit $[9,10]$.

Berdasarkan studi pendahuluan untuk menggambarkan permasalahan yang penulis lakukan di rumah sakit pada tanggal 16 januari 2020, penulis menemukan masalah dalam hal menganalisis sikap petugas kesehatan dan bentuk tanggung jawab yang diberikan dalam pengisian formulir A dan Formulir B, berdasarkan pengamatan yang penulis lakukan pada 10 berkas rekam medis terdapat 6 berkas yang tidak lengkap (60\%), dan terdapat 4 berkas lengkap (40\%), terutama pada item data yang di isi oleh case manager, ketidaklengkapan itu sering terdapat pada tanggal masuk, tanggal keluar, ruangan rawat, kelas rawatan dan penilain skor baik itu kategori mayor ataupun minor, dimana data yang sering ditemukan ketidaklengkapan dalam pengisian formulir A dan Formulir B oleh petugas, hal ini berkaitan dengan sikap dan bentuk rasa tanggung jawab petugas dalam pengisian formulir A dan Formulir B di rumah sakit belummaksimal ,faktor ketidak lengkapan pengisian formulir A dan Formulir B disebabkan oleh waktu yang sangat terbatas dan pasien yang banyak sehingga case manager terburu-buru dalam pengisian formulir A dan Formulir B, dan masih adanya formulir yang tidak lengkap atau belum di isi.

Penulis juga melakukan wawancara dalam upaya mendapatkan gambaran permasalahan kepada kepala ruangan ambun pagi dan 2 (dua) orang petugas yang melakukan assesment kelengkapan pada formulir A dan Formulir B, diperoleh informasi bahwa dampak dari masalah yang terjadi apabila pengisian formulir a dan b tidak lengkap itu akan membuat kualitas data tidak baik dan tidak akurat ,ini disebabkan oleh tanggung jawab petugas yang tidak maksimal dalam mengisi kelengkapan formulir a dan formulir $b$, karena salah satu syarat akreditasi rumah sakit adalah kelengkapan dan keakuratan dalam pengisian dokumen rekam medis dan dampak yang timbulkan dari ketidak lengkapan pengisian Formulir A dan Formulir B adalah tidak maksimalnya kinerja rumah sakit pada bagian bangsal embun pagi, pengisian formulir A dan Formulir B mempunyai keterkaitan pada remunerasi (pemberian gaji kepada pegawai), dari permasalah yang penulis temukan dapat di asumsikan bahwa tanggung jawab petugas pada pengisian Formulir A dan B 
belum baik. Berdasarkan Permen Nomor 129 Tahun 2008 tentang standar pelayanan Minimal Rumah sakit menyebutkan bahwa pengisian informed consent wajib lengkap $100 \%$, untuk Pemenuhan standar Pelayanan Rumah sakit digunakan untuk peningkatan mutu pelayanan Rumah sakit [11].

\section{METODE PENELITIAN}

Penelitian ini menggunakan metode literature review atau studi kepustakaan. Literature review adalah metode yang mengidentifikasi, menilai dan menginterprestasi seluruh temuan-temuan pada suatu topik penelitian (research question) yang telah ditetapkan sebelumnya (Kitchenham \& Charters 2007) tentang literature review Analisis kelengkapan pengisian Formulir A (Evaluasi awal MPP) dan formulir B (Catatan Implementasi).

Kriteria inklusi menjadi subjek dalam penelitian yang dapat mewakili sample, untuk memenuhi beberapa syarat sebagai sample [12] yaitu :

1. Jurnal yang terbit 6 tahun terakhir (2015-2020)

2. Jurnal yang memiliki ISSN

3. Full teks bisa dibaca atau di download

4. Kata kunci penelitian sesuai.

Sedangkan kriteria ekslusi merupakan kriteria yang berkaitan dengan subjek yang tidak dapat mewakili sample, karena kriteria tersebut tidak dapat memenuhi syarat untuk sample penelitian [12]:

1. Jurnal tidak ada ISSN

2. Artikel yang tidak bisa dibuka full teks dan tidak bisa di download.

\section{HASIL DAN PEMBAHASAN}

\subsection{Hasil}

\section{Hasil Study Literature Review}

Tabel 1. Hasil Telaah Beberapa Artikel Berdasarkan Metode, Hasil, Kelemahan, dan Keunggulan

\begin{tabular}{|c|c|c|c|c|c|c|}
\hline No & Tujuan & Judul & Metode & Hasil & Kelemahan & Keunggulan \\
\hline 1 & $\begin{array}{l}\text { Mendeskrip } \\
\text { sikan } \\
\text { kelengkapa } \\
\text { n data } \\
\text { formulir A } \\
\text { (Evalusi } \\
\text { awal Mpp) } \\
\text { Dan } \\
\text { Formulir B } \\
\text { (catatan } \\
\text { Implementa } \\
\text { si) }\end{array}$ & $\begin{array}{l}\text { Analisi } \\
\text { kelengkap } \\
\text { an } \\
\text { pengisian } \\
\text { Berkas } \\
\text { Rekam } \\
\text { Medis } \\
\text { Pasien } \\
\text { Rawat } \\
\text { Inap } \\
\text { RSUP } \\
\text { Dr.Kariadi } \\
\text { Semarang } \\
\text { 2019 [13]. }\end{array}$ & $\begin{array}{l}\text { Penelitian } \\
\text { yang } \\
\text { digunakan } \\
\text { adalah } \\
\text { penelitian } \\
\text { kualitatif }\end{array}$ & $\begin{array}{l}\text { Berdasarkan } \\
\text { hasil penelitian } \\
\text { diperoleh data } \\
\text { bahwa } \\
\text { kelengkapan } \\
\text { dikatakan } \\
\text { cukup tinggi } \\
\text { untuk } \\
\text { pengisian } \\
\text { berkas pada } \\
\text { rekam medis } \\
\text { berdasarkan } \\
\text { ke-empat } \\
\text { aspek. Hal ini } \\
\text { berarti angka } \\
\text { ketidaklengka } \\
\text { pan rendah }\end{array}$ & $\begin{array}{l}\text { Pengisian data pada } \\
\text { berkas rekam medis } \\
\text { untuk rawat inap } \\
\text { belum secara } \\
\text { spesifik. Unsur } \\
\text { motivation, tidak } \\
\text { ada sanksi yang } \\
\text { tegas terkait dengan } \\
\text { petugas yang tidak } \\
\text { mengisi berkas } \\
\text { secara lengkap dan } \\
\text { tidak adanya } \\
\text { pendorong } \\
\text { semangat bekerja } \\
\text { seperti adanya } \\
\text { penghargaan,hadiah } \\
\text { atau sekedar pujian } \\
\text { kepada petugas }\end{array}$ & $\begin{array}{l}\text { Berdasarkan } 9 \\
\text { komponen } \\
\text { data identitas, } \\
\text { terdapat } 86 \\
\text { berkas rekam } \\
\text { medis yang } \\
\text { sudah diisi } \\
\text { secara benar. } \\
\text { Sedangkan } \\
\text { terdapat } 0 \\
\text { berkas yang } \\
\text { tidak diisi } \\
\text { sesuai dengan } \\
9 \text { komponen } \\
\text { tersebut. } \\
\text { Komponen } \\
\text { yang menjadi } \\
\text { sampel, yang } \\
\text { terdapat dalam } \\
\text { berkas medis } \\
\text { yaitu terdapat } \\
\text { data sosial }\end{array}$ \\
\hline
\end{tabular}


yang sudah

diisi lengkap

dan benar.

Kategori benar

yaitu sesuai

dengan kartu

identitas yang

dimiliki oleh

pasien

tersebut.

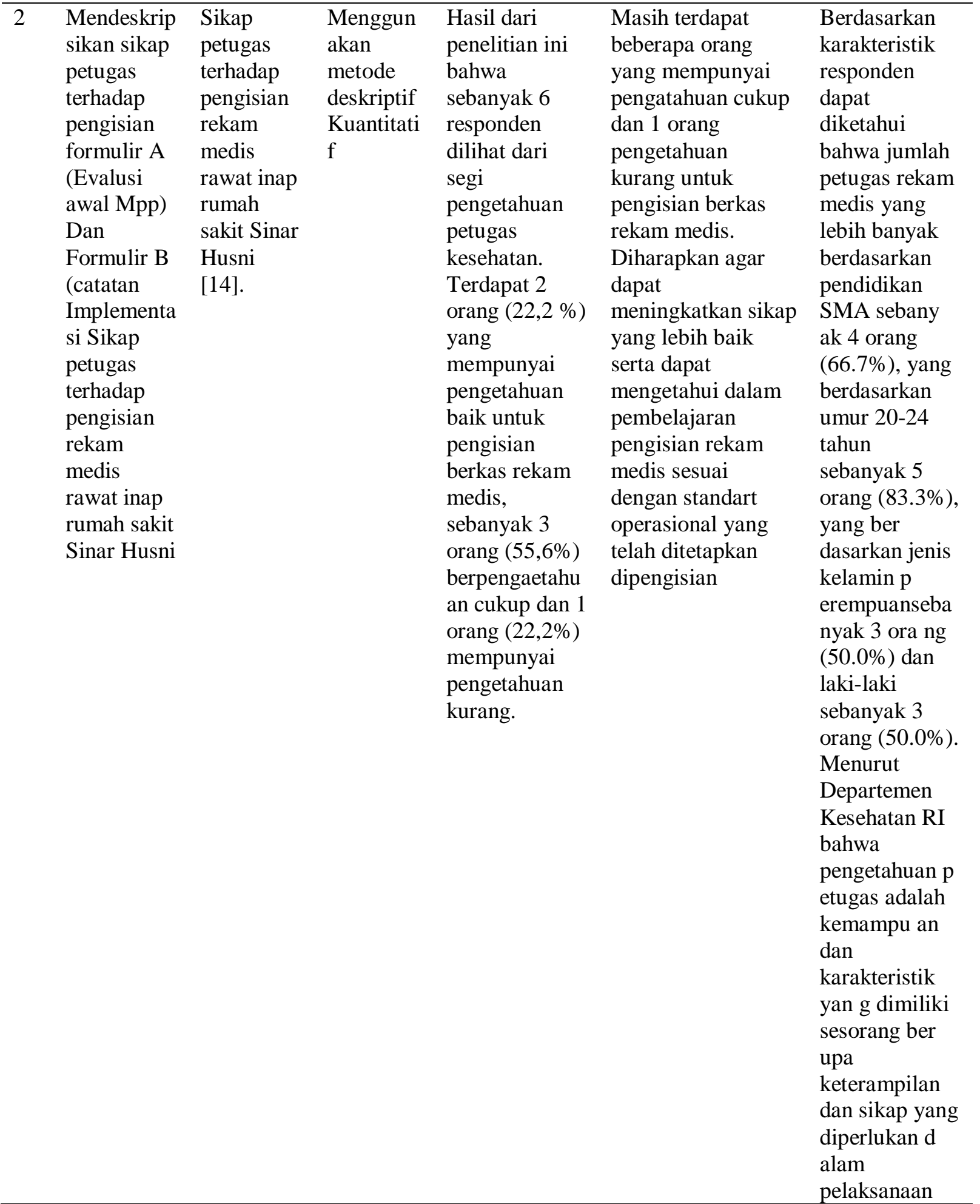

Jurnal Ilmiah Perekam dan Informasi Kesehatan Imelda, Vol. 6, No. 1, Februari 2021:31-41 


\begin{tabular}{|c|c|c|c|c|c|c|}
\hline & & & & & & $\begin{array}{l}\text { tugas dan } \\
\text { jabatan yang } \\
\text { dilakukan } \\
\text { secara } \\
\text { professional, } \\
\text { efektif, dan } \\
\text { efisien. }\end{array}$ \\
\hline 3 & $\begin{array}{l}\text { Mendeskrip } \\
\text { sikan sikap } \\
\text { yang } \\
\text { dimiliki } \\
\text { oleh } \\
\text { petugas } \\
\text { kesehatan } \\
\text { dalam } \\
\text { pengisian } \\
\text { formulir A } \\
\text { (Evalusi } \\
\text { awal } \\
\text { Mpp)D an } \\
\text { Formulir B } \\
\text { (catatan } \\
\text { Implementa } \\
\text { si }\end{array}$ & $\begin{array}{l}\text { Pengaruh } \\
\text { sikap } \\
\text { petugas } \\
\text { rekam } \\
\text { medis } \\
\text { terhadap } \\
\text { kelengkap } \\
\text { an } \\
\text { pengisian } \\
\text { formulit } \\
\text { pemeriksa } \\
\text { an pasien } \\
\text { rawat inap } \\
\text { di Rumah } \\
\text { Sakit } \\
\text { Umum } \\
\text { Herna } \\
\text { Medan } \\
\text { tahun } 2015 \\
\text { [15]. }\end{array}$ & $\begin{array}{l}\text { Menggun } \\
\text { akan } \\
\text { metode } \\
\text { penelitian } \\
\text { deskriptif }\end{array}$ & $\begin{array}{l}\text { Hasil yang } \\
\text { diketahui } \\
\text { maka nilai } \\
\text { sikap respo } \\
\text { nden yang } \\
\text { baik ada } 4 \\
\text { responden } \\
\text { (40\%), dan } \\
\text { sikapnya } \\
\text { cukup ada } 6 \\
\text { responden } \\
(60 \%) .\end{array}$ & $\begin{array}{l}\text { Program kerja dan } \\
\text { kinerja petugas } \\
\text { tenaga kesehatan } \\
\text { masih kurang, } \\
\text { diharapkan agar } \\
\text { petugas dapat } \\
\text { memberikan data } \\
\text { yang lebih akurat }\end{array}$ & $\begin{array}{l}\text { Sikap } \\
\text { diperoleh } \\
\text { petugas rekam } \\
\text { medis dengan } \\
\text { menggunakan } \\
\text { kuisioner } \\
\text { sudah baik }\end{array}$ \\
\hline 4 & $\begin{array}{l}\text { Mendeskrip } \\
\text { sikan } \\
\text { tanggung } \\
\text { jawab } \\
\text { petugas } \\
\text { terhadap } \\
\text { pengisian } \\
\text { formulir A } \\
\text { (Evalusi } \\
\text { awal Mpp) } \\
\text { Dan } \\
\text { Formulir B } \\
\text { (catatan } \\
\text { implementa } \\
\text { si) }\end{array}$ & $\begin{array}{l}\text { Analisis } \\
\text { kepatuhan } \\
\text { pengisian } \\
\text { Berkas } \\
\text { Rekam } \\
\text { Medis di } \\
\text { Instalsi } \\
\text { Rawat } \\
\text { Inap } \\
\text { Rumah } \\
\text { Sakit X } \\
2019 \text { [16]. }\end{array}$ & $\begin{array}{l}\text { Metode } \\
\text { yang } \\
\text { digunakan } \\
\text { yaitu } \\
\text { deskriptif } \\
\text { kualitati }\end{array}$ & $\begin{array}{l}\text { Segi sikap dari } \\
\text { tenaga } \\
\text { kesehatan } \\
\text { (dokter dan } \\
\text { petugas PPA } \\
\text { lainnya yang } \\
\text { berperan) } \\
\text { sudah } \\
\text { menyadari dan } \\
\text { mengetahui } \\
\text { tanggungjawa } \\
\text { bnya dalam } \\
\text { peran } \\
\text { melengkapi isi } \\
\text { rekam medis, } \\
\text { baik itu ditulis } \\
\text { secara manual } \\
\text { maupun } \\
\text { online, sesuai } \\
\text { dengan standar } \\
\text { yang yang } \\
\text { diberikan oleh } \\
\text { Konsil } \\
\text { Kedokteran } \\
\text { Indonesia } \\
\text { tahun } 2006\end{array}$ & $\begin{array}{l}\text { Desain yang } \\
\text { terdapat dalam } \\
\text { rekam medis dalam } \\
\text { penelitian ini cukup } \\
\text { baik, meskipun } \\
\text { ada beberapa point } \\
\text { yang tidak perlu } \\
\text { dimasukkan, } \\
\text { sehingga hal ini } \\
\text { menjadi salah satu } \\
\text { faktor petugas } \\
\text { kesehatan (dokter) } \\
\text { malas untuk } \\
\text { mengisi data } \\
\text { tersebut. }\end{array}$ & $\begin{array}{l}\text { Sudah } \\
\text { memiliki SOP } \\
\text { dan responden } \\
\text { mengetahui } \\
\text { cara-cara } \\
\text { penulisan } \\
\text { rekam medis } \\
\text { yang benar } \\
\text { dan baik } \\
\text { secara umum. }\end{array}$ \\
\hline 5 & $\begin{array}{l}\text { Mendiskrip } \\
\text { sikan } \\
\text { sumber }\end{array}$ & $\begin{array}{l}\text { Analisis } \\
\text { sistem } \\
\text { penyeleng }\end{array}$ & $\begin{array}{l}\text { Metode } \\
\text { penelitian } \\
\text { yang }\end{array}$ & $\begin{array}{l}\text { Sistem } \\
\text { penyelenggara } \\
\text { an berkas }\end{array}$ & $\begin{array}{l}\text { Berdasarkan hasil } \\
\text { penelitian yang } \\
\text { dilakukan dapat }\end{array}$ & $\begin{array}{l}\text { Berdasarkan } \\
\text { kompetensi } \\
\text { yang }\end{array}$ \\
\hline
\end{tabular}




\begin{tabular}{|c|c|c|c|c|c|}
\hline $\begin{array}{l}\text { daya } \\
\text { manusia } \\
\text { yang } \\
\text { terlibat } \\
\text { pengisian } \\
\text { Formulir A } \\
\text { (Evaluasi } \\
\text { awal Mpp) } \\
\text { dan } \\
\text { Formulir B } \\
\text { (Catatan } \\
\text { Implementa } \\
\text { si) }\end{array}$ & $\begin{array}{l}\text { garaan } \\
\text { Rekam } \\
\text { Medis di } \\
\text { Instalsi } \\
\text { Rekam Me } \\
\text { dis RS"X" } \\
\text { Tangerang } \\
\text { April Mei } \\
2015 \text { [17]. }\end{array}$ & $\begin{array}{l}\text { digunakan } \\
\text { adalah } \\
\text { metode } \\
\text { Kualitatif }\end{array}$ & 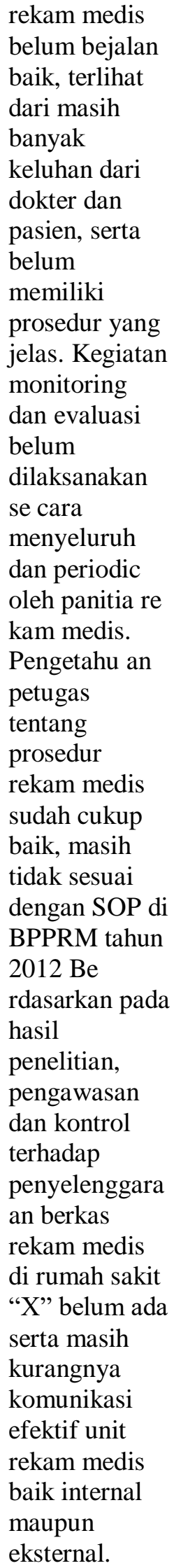 & $\begin{array}{l}\text { diambil kesimpula } \\
\text { n bahwa: Panitia } \\
\text { rekam medis } \\
\text { hendaknya mulai } \\
\text { melaksanakan } \\
\text { fungsi monitoring } \\
\text { dan evaluasi } \\
\text { penyelenggaraan } \\
\text { rekam medis setiap } \\
\text { bulan terutama } \\
\text { mengenai analisis } \\
\text { kelengkapan rekam } \\
\text { medis. Merekrut } \\
\text { petugas bagian } \\
\text { distribusi agar } \\
\text { petugas pelaksana } \\
\text { lebih m } \\
\text { engutamakan } \\
\text { tanggung jawabnya } \\
\text { sesuai uraian tugas. } \\
\text { Kepala instalasi } \\
\text { rekam medis } \\
\text { menyusun rencana } \\
\text { kegiatan pelatihan } \\
\text { dan inhouse } \\
\text { training Rumah } \\
\text { sakit untuk petugas } \\
\text { rekam medis } \\
\text { (misalnya pelatihan } \\
\text { coding) }\end{array}$ & $\begin{array}{l}\text { ditentukan } \\
\text { rumah sakit } \\
\text { dan pihak } \\
\text { rumah sakit } \\
\text { mendukung } \\
\text { pendidikan } \\
\text { berkelanjutan. } \\
\text { Sarana dan } \\
\text { Prasarana di } \\
\text { rumah sakit } \\
\text { sudah mulai } \\
\text { ada perbaikan } \\
\text { na mun belum } \\
\text { signifikan. } \\
\text { Sarana yang } \\
\text { kurang } \\
\text { diantaranya } \\
\text { adalah ruang } \\
\text { rekam medis } \\
\text { yang sempit, } \\
\text { serta gang } \\
\text { antar rak } \\
\text { kurang lebar. }\end{array}$ \\
\hline
\end{tabular}




\subsection{Pembahasan}

Dalam menyelesaikan masalah penelitian ini tentang "Analisis kelengkapan Pengisian Formulir A (Evaluasi Awal MPP) dan Formulir B (Catatan Implementasi). Sumber referensi yang digunakan dalam penyusunan penelitian ini berasal dari beberapa artikel sesuai dengan topik penelitian, yang sudah dipublikasikan di beberapa jurnal.

\section{Kelengkapan Data Formulir A (Evaluasi Awal MPP) Dan Formulir B (Catatan Implementasi)}

Penelitian yang dilakukan oleh Selvia Juwita Swari, Gamasiano Alfiansyah, Rossalina Adi Wijayanti, Rowinda Dwi Kurniawati tahun 2019 [13]. Kelengkapan data pada rekam medis berkaitan dengan tindakan sebagai tindakan untuk memvalidasi data identitas pasien, tenaga kesehatan yang berwenang dalam pengisiannya yaitu dokter atau perawat. Dalam berkas rekam medis dapat berupa nama, tanda tangan, diagnosa, legalitas seperti stempel serta inisial sebagai data untuk diidentifikasi.

Bentuk tanggung jawab sangat diperlukan untuk mendorong dokter dan perawat mengisi data secara lengkap. Berdasarkan standar yang sudah ada, seorang dokter diwajibkan mengisi secara lengkap berkas rekam medis dalam waktu $\leq 24$ jam kerja. Pengisian dilakukan setelah selesai pemberian pelayanan, baik pasien rawat inap maupun pasien rawat jalan. Data-data yang wajib diisi yaitu berkaitan dengan identitas, diagnosa atau anamnesa, rencana asuhan yang diberikan, pelayanan yang diberikan, bagaimana tindak lanjut pelayanan, dan resume. Tidak hanya petugas kesehatan yang wajib mengisi kelengkapan berkas, pasien maupun keluarga pasien juga wajib mengisi informed consent, yaitu bentuk persetujuan yang diberikan oleh pasien atau keluarga atas tindakan yang akan diberikan oleh tenaga kesehatan. Hal ini perlu disetujui terlebih dahulu, agar tindakan medis bisa diberikan kepada pasien [7, 18]. Berdasarkan analisa penelitian yang peneliti asumsikan. Kelengkapan dalam pengisian berkas rekam medis sangat penting dilakukan karena salah satu kegunaan dari berkas rekam medis jika dilihat dari aspek hukum merupakan bahan tanda bukti tertulis. Berbagai standard dan aturan dari pemerintah sudah ada, namun masing kurangnya sosialisasi dan tindakan tegas pimpinan, menyebabkan ketidaklengkapan pengisian berkas rekam medis ini sering terjadi.

\section{Sikap Petugas Terhadap Pengisian Formulir A (Evaluasi Awal MPP) Dan Formulir B (Catatan Implementasi)}

Penelitian yang dilakukan oleh Ali Sabela Hasibuan, Melita W Siburian, tahun 2018, yaitu sebanyak 6 responden yang diteliti, terdapat 2 orang yang memiliki sikap yang baik terkait pengisian berkas rekam medis dan yang tidak baik sebanyak 4 orang. Berdasarkan penelitian yang telah dilakukan diketahui bahwa pada umumnya sikap petugas yang baik, disebabkan karena peran dan fungsi penginderaan dimana seseorang dapat menerima stimulus dari suatu object tertentu, dari yang tidak tahu menjadi tahu atau muncul pengetahuan baru terhadap suatu objek tertentu. Sikap atau dikenal dengan istilah attitude adalah bentuk evaluasi diri atau reaksi dari perasaan seseorang. Sikap seseorang bisa dilihat dari perasaan mendukung atau keberpihakan maupun bentuk tidak mendukung atau tidak memihak pada hal tertentu. Bentuk sikap berkaitan erat dengan luapan perasaan, bentuk keyakinan, serta bentuk perilaku yang cenderung menetap pada hal tertentu.

Berdasarkan analisa yang peneliti asumsikan khususnya pada bagian petugas rekam medis diharapkan agar dapat meningkatkan sikap yang lebih baik terhadap pengisian rekam medis. Berdasarkan telaah artikel yang sudah dilakukan, ditemukan bahwa masih kurangnya petugas rekam medis yang belum selalu dengan latar belakang ilmunya, sehingga berpengaruh dalam ilmu dan kemampuan petugas dalam sistem pengisian berkas rekam medis, karena petugas belum sepenuhnya mengetahui tata cara pengisian berkas rekam medis, sebaiknya pihak rumah sakit mengadakan sosialisasi tentang tata cara 
pengisian berkas rekam medis sesuai dengan standart operasional yang telah ditetapkan dipengisian.

\section{Tanggung Jawab Petugas Terhadap Pengisian Formulir A (Evaluasi Awal MPP) Dan Formulir B (Catatan Implementasi)}

Penelitian yang dilakukan oleh Gita Kencana, Grace Rumengan, Fresley Hutapea tahun 2019. Pada wawancara mendalam yang dilakukan, secara general responden menjawab bahwa bentuk tanggung jawab dalam pengisian rekam medis pada petugas professional pemberi asuhan utamanya yaitu dokter, perawat dan tenaga kesehatan yang memberikan pelayanan secara langsung kepada pasien. Dilihat dari segi sikap tenaga kesehatan yang terkait dalam pengisian berkas rekam medis ini, sudah menyadari tanggung jawabnya, sejalan dengan manual rekam medis yang diterbitkan oleh Konsil Kedokteran Indonesia tahun 2006. Salah satu nilai karakter yang perlu ditanamkan dalam setiap individu dalam bekerja yaitu adanya rasa tanggung jawab, agar kepekerjaan bisa terlaksana sesuai mana mestinya [19].

Penulisan pada form rekam medis menjadi suatu hal yang penting, karena mempengaruhi kelengkapan data pada berkas rekam medis. Berdasarkan analisa peneliti, bahwa masih kurangnya tanggung jawab petugas akan kelengkapan dokumen rekam medis. Pengisian berkas yang tidak lengkap akan berpengaruh kepada pemberian informasi yang tidak lengkap kepada pasien, terkait dengan informasi pengobatan, serta berpengaruh pada tindak lanjut jika pasien datang kembali berobat ke pelayanan kesehatan. Rekam medis yang tidak lengkap tidak cukup memberikan informasi untuk pengobatan selanjutnya ketika pasien datang kembali ke sarana pelayanan kesehatan, Rekam medis ini tidak memiliki dokumen yang sepantasnya. Berdasarkan telaah artikel tersebut ditemukan bahwa, adanya respon dari dokter yang mengatakan bahwa mereka melakukan pengisian berkas rekam medis sudah sesuai SPO. Tetapi dari data yang diambil masih ditemukan berkas RM yang tidak lengkap, dimana seharusnya diisi oleh dokter yang memberikan pelayanan tersebut.

\section{Sumber Daya Manusia Yang Terlibat Pengisian Formulir A (Evaluasi awal MPP) dan Formulir B (Catatan Implementasi)}

Berdasarkan penelitian yang dilakukan oleh Novita Nuraini tahun 2015, yang termasuk dalam indikator masukan (input) yaitu Sumber Daya Manusia (SDM), fasilitas, Standar Operasional Prosedur, dan material. Hasil penelitian ditemukan bahwa masih kurangnya jumlah petugas rekam medis, dikarenakan tidak adanya petugas bagian distribusi untuk mengirimkan berkas ke bagian Hemodialisa, ruangan IGD, dan ruangan rawat inap. Disamping itu, masih ditemukan juga petugas rekam medis tidak menjalankan tugasnya dengan semestinya sesuai dengan uraian tugas yang sudah dituangkan dalam dokumen rumah sakit [20].

Menurut (Sutrisno, 2014) bahwa sumber daya manusia merupakan sumber daya yang berkaitan dengan perasaan, adanya keinginan, bentuk keterampilan, adanya pengetahuan, motivasi, serta adanya daya dan karya [21]. Semua potensi yang dimiliki oleh SDM tersebut akan memberi pengaruh terhadap pekerjaan dalam organisasi atau unit untuk mencapai tujuan. Berdasarkan buku dari Dr. Mamik, SDM meupakan suatu bentuk kemampuan yang berkaitan dengan daya fikir dan kemampuan fisik. Karakter ini biasanya dipengaruhi oleh keturunan, serta faktor lingkungan sekitar, sedangkan prestari kerja di motivasi oleh keinginan untuk memenuhi kepuasannya. Berdasarkan analisa yang peneliti asumsikan Kurangnya tenaga kerja atau sumber daya manusia yang terlibat dalam pengisian berkas rekam medis dan kurangnya petugas untuk distribusi atau petugas untuk pengiriman berkas rekam medis ke bagian Hemodialisa, ruangan IGD dan ruangan rawat 
inap untuk pasien yang sedang dioperasi. Uraian tugas petugas rekam medis yang disebutkan dalam dokumen rumah sakit tidak berjalan semestinya akibat kurangnya sumber daya manusia pelayanan di rumah sakit.

\section{KESIMPULAN}

Berdasarkan Literature Review dari 10 Jurnal Literature yang dilakukan analisis kelengkapan pengisian formulir A (evaluasi awal MPP) dan formulir B (catatan implementasi). Diperoleh Hasil sebagai berikut:

1. Berdasarkan beberapa artikel yang ditelaah didapatkan kesimpulan bahwa masih ada petugas yang belum melengkapi formulir A dan B rekam medis.

2. Masih adanya petugas yang lalai terhadap pengisian formulir A dan formulir B pada rekam medis, diharapkan petugas rekam medis agar dapat meningkatkan sikap yang lebih baik, sehingga berkas rekam medis bisa terisi secara lengkap.

3. Bentuk tanggung jawab petugas dalam pengisian kelengkapan dokumen rekam medis sudah dilakukan dengan baik.

4. Sumber daya manusia bekerja tidak sesuai dengan latar belakang ilmu yang dimiliki serta masih banyaknya petugas yang bekerja secara merangkap karena jumlahnya masih kurang.

Berdasarkan literature review terhadap beberapa artikel terkait, perlu penelitian lanjut tentang penyebab lain ketidak lengkapan dalam pengisian formulir berkas rekam medis dan kendala yang dialami oleh dokter, perawat, atau petugas rekam medis dalam melakukan pengisian berkas rekam medis.

\section{REFERENCES}

[1] Permenkes RI, Nomor 269/MENKES/PER/III2008 tentang Rekam Medis. Indonesia, 2008.

[2] Pepres RI Nomor 11, Informasi dan Transaksi Elektronik. 2008.

[3] T. Solikhah, ., Pamungkas, T. W., \& Marwati, "Analisis Ketidaklengkapan Pengisian Berkas Rekam Medis di Rumah Sakit PKU Muhammadiyah Yogyakarta," J. Kesehat. Masy. (Journal Public Heal. 4(1), 17-28. https//doi.org/10.12928/kesmas.v4i1.1011, 2014.

[4] T. Solikhah, ., Pamungkas, T. W., \& Marwati, "Analisis Ketidaklengkapan Pengisian Berkas Rekam Medis Di Rumah Sakit Pku Muhammadiyah Yogyakarta," J. Kesehat. Masy. (Journal Public Heal. 4(1), 17-28. https//doi.org/10.12928/kesmas.v4i1.1011, 2014.

[5] D. Mardiawati and D. Leonard, "Analisis Pelaksanaan Pengodean Tindakan Medis Pasien JKN di RSI Siti Rahmah Padang," J. Endur. Kaji. Ilm. Probl. Kesehat., vol. 4, no. 1, pp. 34-44, 2019.

[6] D. Z. Y. Jeshia Saputri, "Studi Literature Review Kelengkapan Resume Medis dan Kelengkapan Diagnosa Medis dalam Ketetapatan Pengkodean Diagnosa Penyakit di BebeRapa Rumah Sakit," Adm. Heal. Inf. J., vol. 1, no. 2, pp. 124-132, 2020.

[7] Depkes RI, Pedoman Penyelenggaraan Prosedur Rekam Medis Rumah Sakit di Indonesia. Indonesia, 2006.

[8] Menteri Kesehatan, Peraturan Menteri Kesehatan RI Nomor 1171 tentang Sistem Informasi Rumah Sakit. Indonesia, 2011, pp. 2-5.

[9] D. Leonard, "Pengorganisasian Klaim Pelayanan Pasien JKN di RSUP Dr M. Djamil Padang," Menara Ilmu, vol. X, no. 72, pp. 168-177, 2016.

[10] D. M. Putra, D. Z. Yasli, D. Leonard, and Y. Yulia, "Penerapan Sistem Informasi Manajemen Puskesmas (SIM-PUS) pada Unit Rekam Medis dan Informasi Kesehatan di PUskesmas Lubuk Buaya Kota Padang," J. Abdimas Saintika, vol. 2, 
pp. 67-72, 2020.

[11] Menteri Kesehatan, Menteri Kesehatan RI Nomor 129 tentang Standar Pelayanan Minimal Rumah Sakit. Indonesia, 2008.

[12] S. Notoatmodjo, Metodologi penelitian kesehatan. Jakarta: PT. Rineka Cipta, 2002.

[13] S. J. Swari, G. Alfiansyah, R. A. Wijayanti, and R. D. Kurniawati, "Analisis Kelengkapan Pengisian Berkas Rekam Medis Pasien Rawat Inap RSUP Dr . Kariadi Semarang," Arter. J. Ilmu Kesehat., vol. 1, no. 1, pp. 50-56, 2019.

[14] A. S. Hasibuan, M. W. Siburian, and S. Medan, "Sikap Petugas terhadap Pengisian Rekam Medis Rawat Inap di Rumah Sakit Sinar Husni Tahun 2017," J. Ilm. Perekam dan Inf. Kesehat. Imelda, vol. 3, no. 1, pp. 363-369, 2018.

[15] F. Lubis, "Pengaruh Sikap Petugas Rekam Medis terhadap Kelengkapan Pengisian Formulir Pemeriksaan Pasien Rawat Inap di Rumah Sakit Umum Herna Medan Tahun 2015," J. Ilm. Perekam dan Inf. Kesehat. Imelda, vol. 1, no. 1, pp. 30-35, 2016.

[16] G. Kencana, G. Rumengan, and F. Hutapea, "Analisa Kepatuhan Pengisian Berkas Rekam Medis di Instalasi Rawat Inap Rumah Sakit X Analysis of Medical Record Filling Completeness," J. Manaj. Kesehat. Yayasan RS. Dr. Soetomo, vol. 5, no. 1, pp. 27-37, 2019.

[17] N. Nuraini, "Analisis Sistem Penyelenggaraan Rekam Medis di Instalasi Rekam Medis RS ' $\mathrm{X}$ ' Tangerang Periode April-Mei 2015,” J. ARSI (Administrasi Rumah Sakit Indones., vol. 1, pp. 147-158, 2015.

[18] I. S. Devid Leonard, "Penerapan Kegiatan Analisa Kuantitatif Rekam Medis Rawat Inap pada Ruang Marwa di RSI Siti Rahmah Padang," Adm. Heal. Inf. J., vol. 1, no. 1, pp. 27-35, 2020.

[19] B. A. B. Ii, "Upaya Meningkatkan Tanggung Jawab..., Hana Catur Saputri, FKIP UMP, 2013. 9-37.," 2012.

[20] N. Nuraini, Analisis Sistem Penyelenggaraan Rekam Medis di Instalasi Rekam Medis Rs “X” Tangerang April-Mei 2015. 2015.

[21] Sutrisno, Sumber Daya Manusia halaman 11-36. 2014.

\section{BIOGRAPHIES OF AUTHORS}

\begin{tabular}{|l|l|}
\hline & $\begin{array}{l}\text { Dicho Zhuhriano Yasli, SKM., M.Kes. Tamatan S1 Ilmu Kesehatan Masyarakat di } \\
\text { Universitas Baiturrahmah dan S2 Ilmu Kesehatan Masyarakat di Universitas } \\
\text { Sumatera Utara. Saat ini aktif sebagai Dosen Program Studi S1 Administrasi Rumah } \\
\text { Sakit di STIKes Dharma Landbouw Padang. }\end{array}$ \\
\hline & $\begin{array}{l}\text { Devid Leonard, SKM., M.KM. Tamatan S1 Ilmu Kesehatan Masyarakat di } \\
\text { Universitas Andalas dan S2 Ilmu Kesehatan Masyarakat di Universitas Padjajaran. } \\
\text { Saat ini aktif sebagai Dosen Program Studi S1 Administrasi Rumah Sakit di STIKes } \\
\text { Dharma Landbouw Padang. }\end{array}$ \\
\hline
\end{tabular}

Jurnal Ilmiah Perekam dan Informasi Kesehatan Imelda, Vol. 6, No. 1, Februari 2021:31-41 


\begin{tabular}{|l|l|}
\hline & Berly Nisa Srimayarti, SKM., M.KM. Tamatan S1 Ilmu Kesehatan Masyarakat di \\
Universitas Andalas dan S2 Ilmu Kesehatan Masyarakat di Universitas Indonesia. \\
Saat ini aktif sebagai Dosen Program Studi S1 Administrasi Rumah Sakit di STIKes \\
Dharma Landbouw Padang.
\end{tabular}

